\title{
Intermediate fertile Triticum aestivum (+) Agropyron elongatum somatic hybrids are generated by low doses of UV irradiation
}

\author{
Ai Xia CHENG, Guang Min XIA*, Da Ying ZHI, Hui Min CHEN \\ School of Life Sciences, Shandong University, Jinan 250100, Shandong, China.
}

\begin{abstract}
We report the production and characterization of somatic hybrids between Triticum aestivum L. and Agropyron elongatum (Host) Nevishi (the synonym is Thinopyrum ponticum). Asymmetric protoplast fusion was performed between Agropyron elongatum protoplasts irradiated with a low UV dose and protoplasts of wheat taken from nonregenerable suspension cultures. More than 40 green plantlets were obtained from 15 regenerated clones and one of them produced seeds. The phenotypes of the hybrid plants and seeds were intermediate between wheat and Agropyron elongatum. All of the regenerated calli and plants were verified as intergeneric hybrids on the basis of morphological observation and analysis of isozyme, cytological, 5SrDNA spacer sequences and random amplified polymorphic DNA (RAPD). RFLP analysis of the mitochondrial genome revealed evidence of random segregation and recombination of mtDNA.
\end{abstract}

Keywords: Triticum aestivum, Agropyron elongatum, somatic hybridization, mitochondrial genome.

\section{INTRODUCTION}

To keep pace with the continuing increase in the world population, a sufficient food supply can only be achieved by various improvements in the productivity of major cereal crops, including wheat. Somatic hybridization has the potential to be used as a plant breeding technique due to the possibility that it affords to combine sexually incompatible species, and to transfer both nuclear and cytoplasmic gene (s) simultaneously. However, only limited success has been achieved to date in Gramineae[1-5] and especially in wheat [6-8]. Agropyron elongatum is a perennial grass that expresses certain traits that would improve wheat for protein content, disease resistance and particularly salinity tolerance. The hybrids of Triticum aestivum and $A$. elongatum produced by sexual crossing have been previously reported[9-10]. But the traditional work is tedious and time consuming. This disadvantage may be overcome by asymmetric somatic hybridization. Additionally, in contrast to sexual hybrids, somatic hybrids can include cytoplasmic genomes of the fusion parents and this has the potential to derive novel variability[2,8]. Two sorts of somatic hybrid progenies have been obtained from asymmetric and symmetric fusions of wheat $(+) A$. elongatum. One (from symmetric somatic hybridization[11]) resembled A. elongatum, and the other (from asymmetric somatic hybridization[8]) resembled wheat. In the present work,

*Correspondence author: Guang Min XIA

Fax: +86-531-8565610, E-mail: Xiagm@sdu.edu.cn we performed asymmetric protoplast fusion with a lower dose of UV radiation of the donor protoplasts. It is interesting that the phenotype of the regenerated hybrids obtained is intermediate between wheat and A. elongatum with chromosomes ranged from 58-64. The chromosome number of the hybrids obtained from the asymmetric hybridization using higher UV dosage ranged from 40-44, and most of them had a normal wheat chromosome number $(2 n=42)[12]$, which gave evidence on the effect of UV dosage on the donor chromosome elimination in somatic hybridization. In addition, we confirmed the hybrid status of the regenerated calli and plants with biochemical and molecular markers. This type of hybrid can't be obtained by sexual progress and provide a new germplasm for grass and wheat breeding.

\section{MATERIALS AND METHODS}

Common wheat cv. Jinan $177(2 \mathrm{n}=6 \mathrm{x}=42)$ and A. elongatum $(2 n=10 x=70)$ were used as fusion parents. Suspension cultures of wheat were prepared from an embryogenic callus line that has been maintained in long-term culture, as previously described[13]. The induction, sub-culture and selection of embryo-derived calli of $A$. elongatum have been described elsewhere[11]. Protoplasts were isolated from non-regenerable suspension cultures of wheat and embryogenic calli of $A$. elongatum as previously described[11,13]. After isolation and purification, monolayer protoplasts of $A$. elongatum were placed on $3 \mathrm{~cm}$ petri dishes, and UV-irradiated at an intensity of $260 \mu \mathrm{W} / \mathrm{cm}^{2}$ for $30 \mathrm{~s}$. Protoplast fusion and culture were carried out as described by Xia et al[7].

Chromosome numbers in metaphase cells of the fusion parents 
and regenerated calli were counted in chromosome spreads. For this, freshly regenerated calli of the parents and putative hybrids were excised and pre-treated in water $\left(0^{\circ} \mathrm{C}\right)$ for $24 \mathrm{~h}$, and then fixed in ethanol: glacial acetic acid (3:1) for at least $12 \mathrm{~h}$. After rinsing in water for $20 \mathrm{~min}$, they were incubated in an enzyme mixture ( $1 \%$ cellulase Onozuka RS, $0.3 \%$ pectolyase Y-23, $0.6 M$ mannitol, $5 \mathrm{~m} M \mathrm{CaCl}_{2}$, $\mathrm{pH} 5.8$ ) at $37^{\circ} \mathrm{C}$ for $45 \mathrm{~min}$, rinsed in water gently for $30 \mathrm{~min}$ and then fixed in $70 \%$ ethanol. The material was transferred to a clean slide and squashed to spread the chromosomes. The chromosome spreads were stained by standard aceto carmine methods.

Post-fusion products were genotyped by analysis of profiles of isozymes, RAPDs, specific PCR (5SrDNA spacer) and organellar RFLPs. Esterase and peroxidase profiles were generated from PAGE in $4 \%-10 \%$ gels, following the procedures of Xia et al [7]. For PCR and RFLP, DNA was extracted from calli or leaves of putative hybrids and parents according to the modified CTAB method. RAPD reaction mixtures consisted of $10 \times$ PCR buffer; $20 \mu M \mathrm{dNTPs} ; 2.5$ $\mathrm{mM} \mathrm{MgCl}$; 20 ng primer (Operon Technology, USA); Ampli Taq polymerse $1 \mathrm{U}$ and $50 \mathrm{ng}$ of genomic DNA in a total volume of $20 \mu \mathrm{l}$. PCR amplification was carried out in a programmable thermal controller (PTC-100 ${ }^{\mathrm{TM}}$ ): denaturation $-3 \mathrm{~min}$ at $94{ }^{\circ} \mathrm{C}$, followed by 43 cycles of $10 \mathrm{~s}$ at $94^{\circ} \mathrm{C}, 30 \mathrm{~s}$ at $36^{\circ} \mathrm{C}$, and $50 \mathrm{~s}$ at $72^{\circ} \mathrm{C}$. Finally, the samples were kept at $72^{\circ} \mathrm{C}$ for $7 \mathrm{~min}$. For $5 \mathrm{~S}$ rDNA spacer sequence analysis, the two primers: 5'-GAGAGTAGTACATCGATGGG and 5'-GGAGTTCTGAC-GGGATCCGG were employed. The $25 \mu \mathrm{l}$ reaction mixtures contained $100 \mathrm{ng}$ of genomic DNA, $40 \mathrm{p} M$ of each primer, $200 \mu M$ dNTPs, $2.5 \mathrm{mM} \mathrm{MgCl}$, $1 \mathrm{U}$ Ampli Taq polymerse, $2.5 \mu \mathrm{l} 10 \times \mathrm{PCR}$ buffer. PCR amplification was carried out by a denaturation step of $3 \mathrm{~min}$ at $94^{\circ} \mathrm{C}$, followed by 35 cycles of $94^{\circ} \mathrm{C}$ for $1 \mathrm{~min}, 60^{\circ} \mathrm{C}$ for $1 \mathrm{~min}, 72^{\circ} \mathrm{C}$ for $2 \mathrm{~min}$. A $72^{\circ} \mathrm{C}$ incubation for $10 \mathrm{~min}$ was included as a final extension step. Amplification products were electrophoresed on agarose gels (RAPDs: $1.5 \%, 5 \mathrm{~S}$ rDNA spacer: $2.5 \%$ ) and visualized with UV light after staining with ethidium bromide.

To analyze RFLP in the mitochondrial genome, $20 \mu \mathrm{g}$ of DNA was digested with Hind III or Bam HI.The digested DNA was separated on a $0.7 \%$ agarose gel in TAE buffer and blotted onto a nylon membrane (Hybond $\mathrm{N}^{+}$, Amersham) using 5×SSC. Mt DNA-specific probes atp 6 and cox I were kindly provided by Dr Spangenberg (Institute for Plant science, Swiss Federal Institute of Technology). Probe labeling, hybridization and washing were carried out with the ECL Direct nucleic acid labeling and detection system (ECL RPN3004), according to the manufacturer's instructions.

\section{RESULTS}

\section{Protoplast culture and plant regeneration}

After 35 days of culture, fifteen colonies of 1.5-2 mm in size formed and were transferred onto proliferation medium and later differentiation medium. Shoot formation was observed after two months sub-culture. Shoots were maintained on the same medium until they had reached sufficient size, and were subsequently transferred to NAA-containing medium for root induction. After four months, more than 40 green plantlets were regenerated from 12 colonies. These were considered to be putatively hybrid, because the protoplasts of $A$. elongatum could not divide under the conditions of this experiment and the suspension cultures of wheat had lost their differentiation ability in the course of sub-culture. The appearance of the plants was intermediate between the two parents. For example, leaves of A. elongatum are narrow and prostrate, and the stem emerge from ground level (Fig 1a); but the stems of the regenerated plants are upright and the leaves on the stem are broad and short, as in wheat. In contrast, the morphology of the spikelet resembled that of $A$. elongatum (Fig 1b). Regenerated plants growing in soil were healthy, and three remained green throughout two winters, indicating that they are perennial, which is an important distinguishing feature of A. elongatum. Seeds with intermediate morphology between the parents have been obtained from the regenerated plant produced from clone 2 (Fig 1c).

\section{Hybrid identity of regenerated calli and plants}

As a result of long time sub-culture, the chromosome number of the wheat material had fallen to 21-29, while that of A. elongatum mostly ranged between 42 and 50 . Hybrid chromosome numbers were determined in cells of lines 1, 5 and 14, and these were mostly in the range of 58-64 (Tab 3 and Fig 2). Esterase patterns demonstrated that the profiles of clones 2, 3, 5 and 14 included band (s) characteristic of both parents, along with additional band (s) (Fig 3a). Similarly, the peroxidase profiles showed that these same clones had band(s) specific to both parents (Fig 3b). Nuclear DNA analysis with primers specific for the 5S rDNA spacer showed that calli 1 and 14 amplified characteristic products of both fusion parents (Fig 4a) and plants 2, 3 and 14 had bands characteristic of both fusion parents as well as a new band. In contrast, plant 8 had a pattern identical to A. elongatum. (Fig 4b). Ten RAPD primers identified polymorphic products (Tab 1). The selected three calli (Tab 2 and Fig 5) and plants regenerated from them (Fig 6) were confirmed to be intergeneric hybrids between $T$. aestivum and A. elongatum, as their profiles included product(s) derived from each parent. From above results, some new bands appeared in different analysis, which maybe rose from the recombination of the parent genome.

The RFLP analysis of the mtDNA (Fig 7) showed that clone 14 carried Hind III fragments homologous with atp 6 derived from both parents, along with a novel fragment not present in either parent; while clone 2 had one novel fragment along with only wheat-specific fragments. The other two hybrids had a restriction fragment pattern identical to that of wheat. When the cox I probe was hybridized to Bam HI-digested DNA, all the hybrids had the wheat profile. 


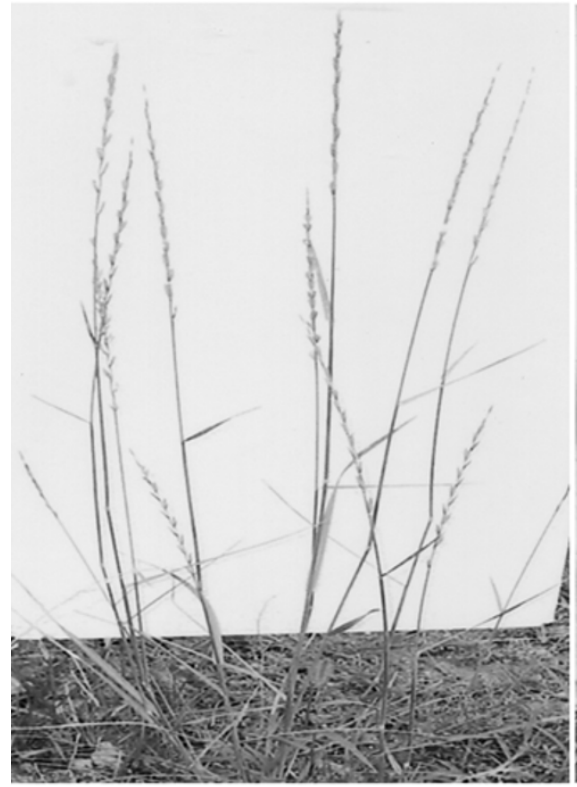

a

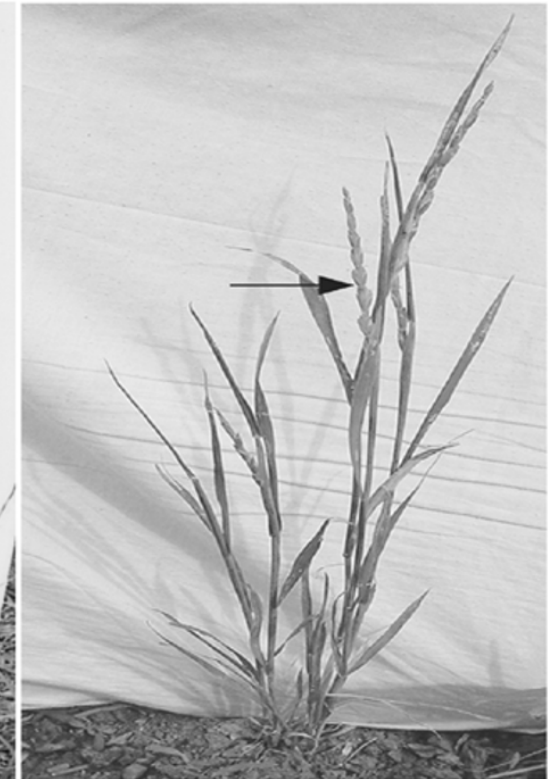

Fig 1. A. elongatum (a); the perennial hybrid (b), $\rightarrow$ : Spike; Seeds of hybrid and parents (c), T: T. aestivum, H: somatic hybrid, P: A. elongatum.

\section{DISCUSSION}

In a previous investigation, highly asymmetric somatic hybrid plants that resembled the wheat parent were obtained, using a higher dose of UV to treat the A. elongatum protoplasts. In this material, GISH showed the presence of only one or two A. elongatum chromosome(s) and /or only chromosome fragment(s) in the hybrid plants[8]. In contrast, the hybrids produced in the present study are intermediate between the two parents. The asymmetric level of the somatic hybrids is influenced by a number of

Tab 1. DNA sequence of RAPD 10-mer primer

\begin{tabular}{llll}
\hline Primer & Sequence & Primer & Sequence \\
\hline OPA1 & CAGGCCCTTC & OPH1 & GGTCGGAGAA \\
OPA4 & AATCGGGCTG & OPH4 & GGAAGTCGCC \\
OPA17 & GGTCCCTGAC & OPH11 & CTTCCGCAGT \\
OPA19 & CAAACGTCGG & OPF12 & ACGGTACCAG \\
OPJ20 & AAGCGGCCTC & & \\
\hline
\end{tabular}

possible internal and external factors, in particular, the dose of irradiation used, the phylogenetic distance between the parental species, the chromosome number of each parent, and the cell cycle of the protoplasts. The most commonly utilized method to produce highly asymmetric hybrids has been to damage the donor protoplasts, pre-fusion, using irradiation (UV-light, $\gamma$-ray). Some experiments showed that $\gamma$-ray had dose dependent effect on the elimination of the donor chromosome in the asymmetric somatic hybridization[14-15], but others showed contrary results[1617]. As for UV light, we reported the chromosome elimination and fragmentation of oat caused by UV irradiation in the hybrid of wheat with oat[18]. But in that experiment, most of oat chromosome was excluded and the chromosome numbers of hybrids from different UV dosage were similar. The increase in dosage mainly resulted in more small donor chromosome fragment production and introgression. So, we suggested that both UV and phylogenetic distance play an important role in the donor chromosome elimination of wheat remote hybrid. In compari-

Tab 2. RAPD analysis of regenerated calli

\begin{tabular}{llllllllll}
\hline Primer & OPA1 & A4 & A17 & A19 & H1 & H4 & H11 & F12 & J20 \\
\hline Clone 2 & T.P & P & N.T.P & N.T.P & T.P & P & T.P & N.T.P & T.P \\
Clone 5 & T.P & P & N.T.P & T.P & T.P & P & T.P & N.T.P & T.P \\
Clone 14 & T.P & P & N.T.P & T.P & T.P & P & T.P & N.T.P & T.P \\
\hline
\end{tabular}

T: wheat, $\mathrm{P}:$ A. elongatum, N: new bands. 
Tab 3. The chromosome number ${ }^{*}$ and the isozyme of the regenerated clones

\begin{tabular}{cccc}
\hline Hybrid number & Chromosome number & Esterase & Peroxidase \\
\hline 1 & $58-64$ & - & - \\
2 & - & $\mathrm{T}+\mathrm{P}+\mathrm{N}$ & $\mathrm{T}+\mathrm{P}$ \\
3 & - & $\mathrm{T}+\mathrm{P}+\mathrm{N}$ & $\mathrm{T}+\mathrm{P}$ \\
5 & $59-61$ & $\mathrm{~T}+\mathrm{P}+\mathrm{N}$ & $\mathrm{T}+\mathrm{P}$ \\
14 & $58-63$ & $\mathrm{~T}+\mathrm{P}$ & $\mathrm{T}+\mathrm{P}$ \\
Wheat & $21-29$ & $\mathrm{~T}$ & $\mathrm{~T}$ \\
\hline
\end{tabular}

T: wheat, P: A. elongatum, N: new bands. ${ }^{*} 100$ cells were counted

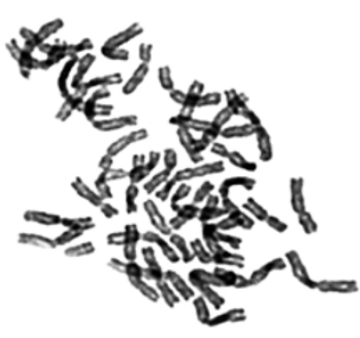

A. elongatum

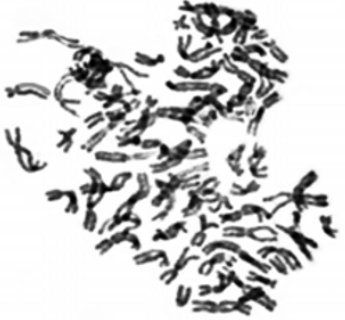

Somatic hybrid

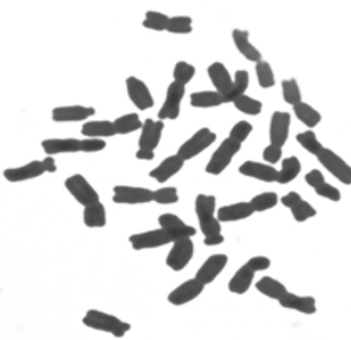

T. aestivum

c

Fig 2. Chromosomes of hybrid line 1 and the parents. (a) A. elongatum, (b) hybrid, (c) parent wheat.

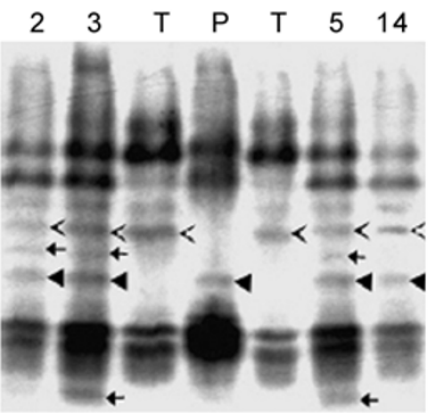

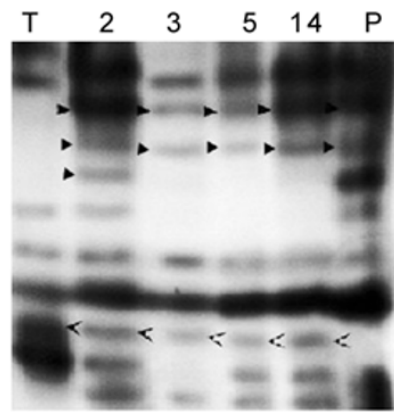

b
Fig 3. Profiles of esterases (a) and peroxidases (b). T: T. aestivum P: A. elongatum $2 ; 3 ; 5 ; 14$ : somatic hybrids. $<$ band characteristic of wheat; 4 band characteristic of A. elongatum; $\uparrow$ band not present in either parent.

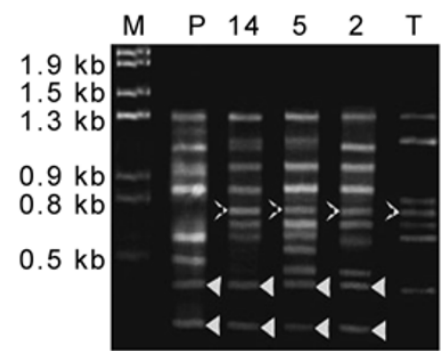

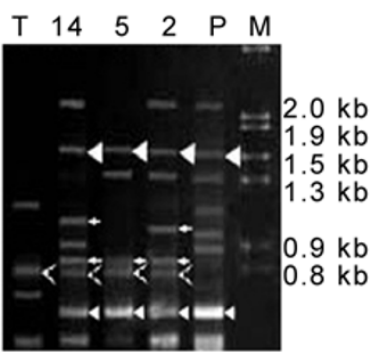

b
Fig 5. RAPD protiles of putative hybrids and their parents amplified from DNA of calli from (a) primer OPA17; (b) primer OPF12. T: wheat, P: A. elongatum 2; 5; 14: putative hybrids. M: $\lambda$ DNA digested by Hind III +EcoR I. < band characteristic of wheat; < band characteristic of A. elongatum; $\leftarrow$ band not present in either parent.

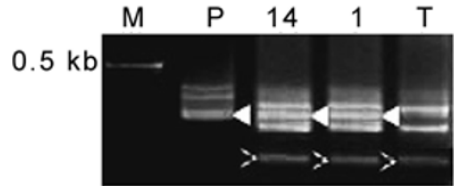

a

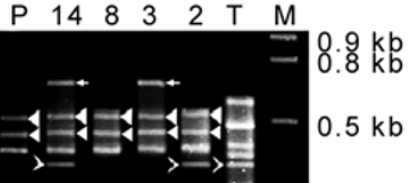

b
Fig 4. 5S rDNA analysis of calli (a) and the leaf (b) of the parents and the regenerated somatic hybrids. T: wheat, P: A. elongatum, $1 ; 2$; $3 ; 8 ; 14$ : somatic hybrids. M: $\lambda \mathrm{DNA} /$ Hind $\mathrm{III}+$ EcoRI molecular marker. $<$ band characteristic of wheat; 4 band characteristic of $A$. elongatum $; \leftarrow$ band not present in either parent.

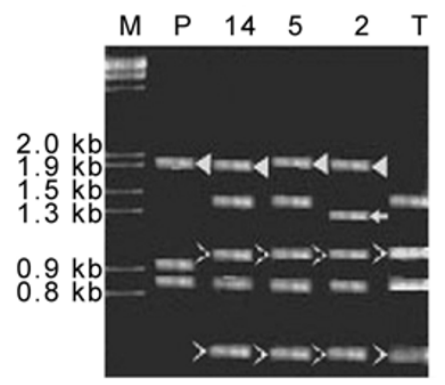

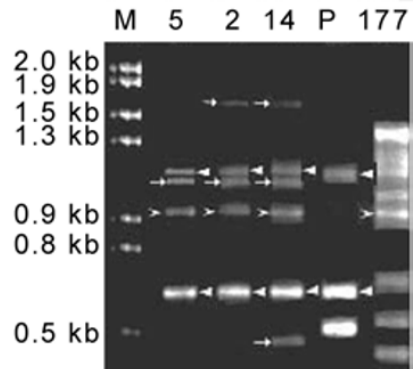

Fig 6. RAPD patterns amplified from leaf DNA of putative hybrids and their parents from (a) primer OPA19; (b) primer OPG14. T: wheat, P: A. elongatum $2 ; 5 ; 14$ : putative somatic hybrids.M: $\lambda \mathrm{DNA} /$ Hind III $+E c o$ RI molecular marker. $<$ band characteristic of wheat; 4 band characteristic of A. elongatum; $\uparrow$ band not present in either parent. 


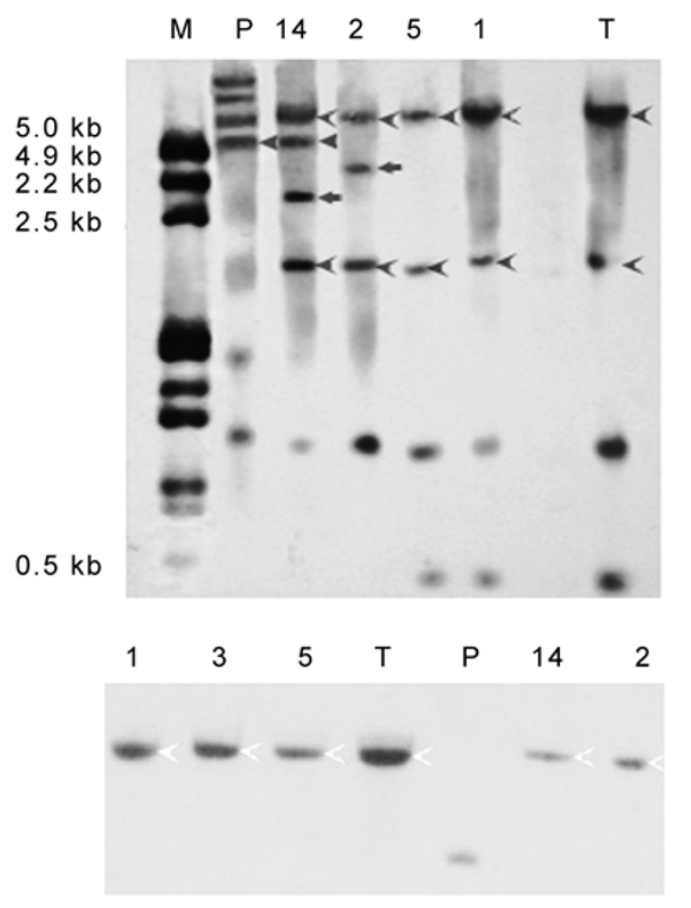

Fig 7. Southern hybridization patterns from HindIII-digested DNA probed with mtDNA probe atp 6 (left) and the BamHI-digested DNA probed with the mtDNA probe cox I (right). T: wheat, P: $A$. elongatum $1 ; 2 ; 3 ; 5 ; 14$ : putative somatic hybrids. M: $\lambda \mathrm{DNA} /$ Hind III $+E c o$ RI molecular marker. < band characteristic of wheat; band characteristic of A. elongatum; $\leftarrow$ band not present in either parent.

son with the highly asymmetric hybrid of wheat and $A$. elongatum [8], we can conclude that hybrids with intermediate phenotype and chromosome number were formed due to the lower dose of UV applied. These hybrids were verified in nature by isozyme, RAPD and RFLP analysis. The result indicated that we could control the quantity of alien genetic material of $A$. elongatum transferred into wheat by using different UV dosage. This result will be useful for the further work to obtain different germplasm by asymmetric somatic hybridization in the related somatic hybridization. So, it is very important both to theory and practice research in asymmetric somatic hybridization induced by UV.

Random segregation and recombination of mtDNA during somatic hybridization has been reported in many plants $[19,20]$. The most likely explanation for mtDNA to undergo genetic rearrangements is its size and its ability to exist in several genomic forms[21]. Conversely, a lack of recombination within the mitochondrial genome has also been reported in Brassica. Moreover preferential amplification of one parental mtDNA was documented in somatic hybrids of the Gramineae[22]. So, the composition patterns of hybrid mt DNA are very different. In the present study, of the Hind III -digested total DNA fragments that hybridized with atp 6, although one clone (No. 14) had specific bands of both parents, the other three clones had only wheat fragments. The A. elongatum cox I sequence was not inherited by any of the clones analyzed. Thus, these somatic hybrids had a predominance of wheat $\mathrm{mt}$ DNA, at least in and around the atp 6 and cox I region. This is only partially consistent with the situation found in symmetric somatic hybrids of wheat with Haynaldia villosa [20], where mitochondria coexisted or recombined. We speculate that the absence of $A$. elongatum mt DNA (as opposed to nuclear DNA) relates to the greater susceptibility of mt DNA to fragmentation as a result of UV treat-ment. The direct impact of UV irradiation on mtDNA has been described in sugar-beet (Beta vulgaris L.) protoplasts by Hall et al[23], who found that UV radiation generated many DNA fragments, with mtDNA appearing to be more sensitive to damage than nuclear DNA.

In conclusion, intermediate hybrid fertile plants have been successfully obtained from the asymmetric somatic hybridization between wheat and A. elongatum, so this procedure is a model experiment for the future, indicating how intergeneric hybrids could be produced from wheat with other related species.

\section{ACKNOWLEDGEMENTS}

This study was supported by National Natural Science Foundation of China, No.30370857, Trans-century Training Program Foundation for the Talents by the Ministry of Education in China, and National High Technology Research and Development Project No. 2001AA241032. We are grateful to Dr. Robert Koebner (John Innes Centre, UK) for language correction.

Received, Jul 16, 2003

Revised, Nov 11, 2003

Accepted, Dec 2, 2003

\section{REFERENCES}

1 Kisaka H, Kisaka M, Kanno A, Kameya T. Intergeneric somatic hybridization of rice (Oryza sativa L.) and barley (Hordeum vulgar L.) by protoplast fusion. Plant Cell Report 1998; 17: 362-7.

2 Kisaka H, Kisaka M, Kanno A, Kameya T. Production and analysis of plants that are somatic hybrids of barly (Hordeum vulgar L.) and carrot (Daucus carota L.). Thero Appl Genet 1997; 94: 221-6.

3 Spangenberg G, Valles MP, Wang ZY, Montavon P, Nagle J, Potrykus I. Asmmetric somatic hybridization between tall fescue (Festuca arundinacea Schreb.) and irradiated Inalian ryegrass (Lolium multiflorum Lam.) protoplasts, Thero Appl Genet 1994; 88:509-19.

4 Liu B, Liu Z, Li XW. Production of a highly asymmetric so- 
matic hybrid between rice and Zizania latifolia (Griseb): evidence for inter-genomic exchange. Thero Appl Genet 1999; 98: 1099-103.

5 Spangenberg G, Wang ZY, Legris G, et al. Intergeneric symmetric and asymmetric hybridization in Festuca and Lolium, Euphytica 1995; 85:235-45.

6 Zhou AF, Xia GM, Chen HM. Asymmetric somatic hybridization between Triticum aestivum L. and Haynaldia villosa Schur. Sci China (Ser C) 1996; 39(6):617-26.

7 Xia GM, Chen HM. Plant regeneration from intergeneric somatic hybridization between Triticum aestivum L. and Leymus chinensis (trin.) Tzvel. Plant Sci 1996; 120:197-203.

8 Xia GM, Xiang FL, Zhou AF, Wang H, Chen HM. Asymmetric somatic hybridization between wheat (Triticum aestivum L.) and Agropyron elongatum (Host) Nevishi. Theor Appl Genet 2003; 107:299-305.

9 Zhou HP, Li B, Li ZS. The study of breeding blue-grain gene translocation of wheat. Acta Bot Boreal Occident Sin 1995; 15 (2):125-8.

10 Li ZS. Remote generic hybridization. In: (Jin SB ed) A Study of Chinese Wheat. China Agriculture Press: Beijing 1995:405-16.

11 Xia GM, Chen HM, Wang H. Somatic hybridization and regeneration capacity complementation between wheat (Triticum aestivum) and Agropyron elongatum. J Shandong Univ (Nat Sci) 1995; 30:325-31.

12 Wang J, Xiang FN, Xia GM, Chen SY, Chen HM. Karyotype analysis of the $\mathrm{F}_{5}$ somatic hybrids between Triticum aestivum and Elytrigia Elongata (Host) Neviski. Journal of Triticeae Crops 2003; 23(1):12-6.

13 Li ZY, Xia GM, Chen HM. Somatic embryogenesis and plant regeneration from protoplast isolated from embryogenic cell suspension of wheat (Triticum aestivum L.). Plant Cell, Tissue Organ Cult 1992; 28:72-85.

14 Zhou AF, Xia GM, Chen HM, Hu H, Comparative study of symmetric and symmetric somatic hybridization between common wheat and Haynaldia villosa. Sci China (Ser C) 2001; 44(3): 294-304.

15 Melzer JM, O Connell MA. Effect of radiation dose on the production of, and the extent of, asymmetry in tomato aymmetric somatic hybrids. Theor Appl Genet 1992; 83:337-44.

16 McCabe PF, Dunbar LJ, Guri A, Sink KC. T-DNA -tagged chromosome 12 in donor Lycopersicon esculentum L. pennellii is retained in asymmetric somatic hybrids with recipient Solanum lycopersicoides. Theor Appl Genet 1993; 86:377-82.

17 Trich H, Zelcer A, Bates GW. Chromosome elimination in asymmetric somatic hybrids: effect of gamma dose and time in culture. Theor Appl Genet 1994; 8:965-72.

18 Xiang FN, Xia GM, Chen HM. Effect of UV dosage on somatic hyridization between common wheat (Triticum aestivum) and Avena sativa L, Plant Sci 2003; 164:697-707.

19 Buiteveld J, Kassies W, Geels R. Biased chloroplast and mitochondrial transmission in somatic hybrids of Allium ampeloprasum L. and Allium cepa L. Plant Sci 1998; 131:21928.

20 Zhou A, Xia G, Zhang X, Chen H, Hu H. Analysis of chromosomal and organellar DNA of somatic hybrids between Triticum aestivum and Haynaldia villosa Schur. Mol Genet Genomics 2001; 265:387-93.

21 Fauron CM-R, Moore B, Casper M. Maize as a model of higher mitochondrial genome plasticity. Plant Sci 1995; 112:11-32.

22 Ozias-Akins P, Tabaeizadeh ZARP, Vasil IK. Preferential amplification of mitochondrial DNA fragments in somatic hybrids of the Gramineae. Curr Genet 1998; 13:241-5.

23 Hall RD, Rouwendal GJA, Krens FA. Asymmetric somatic cell hybridization in plants. Electrophoretic analysis of radiationinduced DNA damage and repair following exposure of sugarbeet (Beta vulgaris L.) protoplasts to UV and gamma rays. Mol Genet Genomics 1992; 234:315-24. 